\title{
Social mobility in China and Britain: a comparative study
}

DOI 10.1515/irsr-2015-0003

Received June 7, 2014; accepted October 27, 2014

\begin{abstract}
This paper looks at social mobility in China and Britain. It explores whether the rapid economic development in China in the last thirty years has brought its mobility closer to that in Britain. It also examines the effects of China's household registration system (hukou) on people's mobility chances. Using national representative surveys in the two countries, we found a convergence in total mobility in the two countries but higher levels of inequality in China in terms of relative mobility. Chinese women faced the greatest disadvantages. The prime driver for social inequality in China was the hukou system. Rural people in China had very limited opportunities for education but even those who had similar levels of education were still very much hampered by the hukou penalty in trying to gain access to advantaged positions. Both societies are highly unequal but China has an additional barrier.
\end{abstract}

Keywords: Social mobility, class, gender, hukou, China, Britain

\section{Introduction}

Social mobility research is concerned with issues of equality of opportunity and the creation of a fair society. Cross-national comparisons depict the patterns and trends in mobility outcomes between societies and aim to uncover the underlying mechanisms of social inequality. Many studies have been conducted in the last few decades both

\footnotetext{
*Corresponding author: Yaojun Li: Department of Sociology and the Cathie Marsh Institute for Social Research, Manchester University, UK, E-mail:Yaojun.Li@manchester.ac.uk

Shun Zhang: Department of Sociology, Xi'an Jiaotong University, China,szhang@mail.xjtu.edu.cn

Jianxun Kong: South Asian Research Institute, Yunnan Academy for Social Sciences, China, jxkong@hotmail.com
}

between capitalist countries and between them and the former socialist countries. Considerable mobility research has also been carried out in China and Britain. Yet there has been, to our knowledge, little research that directly compares the mobility patterns and trends between China and Britain, the two societies characterised by arguably the most different social systems, with the former being the most populous country under state socialism and the latter being the oldest capitalist country in the world. Part of the reason was the difficulty of getting suitable data for the analysis. In this paper, we seek to make a contribution in this regard.

A comparative study between China and Britain seeks to find both differences and commonalities in the two countries just as between capitalist countries, but with an additional angle. While every society is in a sense 'exceptional', there are arguably greater differences between these than between any other randomly selected countries, in terms of political systems, levels of economic development, population size, and cultural traditions. Britain has a democratic polity with a liberal market economy and a large middle class. China has a state socialist polity, a mixed economic structure, and a large agricultural sector. And China's population is 20 times that of Britain. Yet, since the adoption of the reform policy in 1978, China has witnessed unprecedented economic development. From being one of the poorest countries in the world thirty years ago, it is now the second largest economic powerhouse in the world. Does state socialism generate greater equality than that found in a wellestablished capitalist society? Or do family backgrounds play a generally similar role in class reproduction in the two otherwise very different countries? Has the economic development brought mobility patterns in China closer to those found in Britain? What role does China's unique institutional arrangement, the household registration (hukou) system, play in affecting the mobility chances of the Chinese people? And which country has greater gender inequalities? Questions such as these are of considerable importance to our understanding of social inequality in the two countries. 
In this paper, we attempt to address these questions by using national representative sample surveys in the two countries. By harmonising key variables on parental and respondent's class and other socio-demographic variables, we hope to disaggregate the mobility profiles by family origin, gender, cohort and hukou (for China). This would allow us to see whether the processes of social reproduction operate differently in a state socialist as against a liberal capital system, and whether such processes have changed over time, especially in China where the rapid economic development has both significantly enhanced the living standards of the vast majority of the Chinese people and created deepening socio-economic inequality. In addition to descriptive analyses of absolute mobility and statistical modelling on relative mobility, we also conduct a more fine-grained analysis on access to the professional-managerial salariat.

The paper proceeds as follows. In the next section, we give a brief review of theoretical accounts and key findings in existing research on social mobility in the two countries. After that, we introduce the data and methods to be used in the paper, followed by presentation of our findings. Overall, we find a converging pattern in total mobility but a greater inequality in relative mobility in China caused by the hukou barrier. In the final section, we summarise the results with a brief discussion.

\section{Social mobility research and the main findings in Britain and China}

Modernization theories ${ }^{1}$ predict steady, if slow, progress towards greater equality of opportunity for the lower socio-economic class (Parsons, 1967; Blau and Duncan, 1967; Treiman, 1970). Economy development upgrades the occupational structure. In contemporary society driven by technical exigencies and governed by meritocratic

\footnotetext{
1 One might wonder whether contemporary capitalist societies like Britain are still modern or have become 'post-modern'. There has been a lot of discussion on this in the last decade or so, such as Giddens (1991), Bauman (1998), and Beck and Beck-Gernsheim (2002). At the most basic level, the authors believe that, in contemporary capitalist societies, individuals make their own biographies, leaving family origins with little, if any, role to play in shaping mobility trajectories. There have also been powerful critiques of the postmodernist theories from both conceptual and empirical perspectives (Atkinson, 2007a, b, 2008; Chan and Goldthorpe, 2005). This paper does not directly engage with the theories but our analysis offers ample evidence against the individualization thesis. It is also noted here that even though Giddens is one of the most influential theorists, he does have a good appreciation of the importance of family resources on children's mobility chances (Giddens, 2007).
}

ideals, ascriptive factors such as family backgrounds will become less relevant and meritocratic selection based on demonstrated ability and achieved qualifications will assume greater importance. With industrialisation and growth of the service and now the knowledge economy, increasing proportions of the working-age population will move from primary to secondary and then to tertiary sectors of employment, making large-scale social mobility inevitable. At the same time, the bureaucratisation of socio-economic organisations will make the selection process increasingly dependent on accredited skills rather than on direct inheritance (family wealth) or ties of homophily (social connection) although vestiges of such practices will remain in operation in specific sectors. Social mobility will increase, at a level commensurate with economic development, and converge, as national economies in modern societies will become similar under the forces of industrialisation and globalisation, breaking the link between origins and destinations, with achievement replacing ascription. As Britain is one of the most advanced countries in the world and as China's economic development took off only three decades ago, one would expect higher rates of mobility in Britain but converging patterns over time.

While cross-national comparisons tend to disclose numerous phenotypical differences in rates of absolute mobility as can be directly observed from sample surveys due to differences in national economic development and socio-cultural context, mobility research is more concerned with relative mobility (or 'endogenous mobility regimes', Featherman, Jones and Hauser, 1975). While expectations of the modernisation theories on rising and converging mobility have not been met at the relative level, the 'endogenous mobility regimes' theory tries to seek the causes at the genotypical level, namely, the underlying processes for mobility. It is held that in societies with a market economy and a nuclear family structure, the relative mobility rates would be similar (Featherman, Jones and Hauser, 1975). And this similarity is extended to cover state socialist countries, on the condition of a 'substantial uniformity in the economic resources and desirability of occupations' (Grusky and Hauser, 1984: 22). To date, a very impressive body of research has been conducted which lends a general support to the thesis in capitalist and former state socialist countries (Goldthorpe, 1987 and Goldthorpe and Mills, 2008 on Britain; Bukodi and Goldthorpe 2010 on Hungary in its transition from the state socialist economy to the market economy; Breen, 2004 on European countries; Erikson and Goldthorpe, 1985 and Kerckhoff, Campbell and Winfield-Laird, 1985 on the UK-US comparison; Erikson and Goldthorpe, 1992, 
Marshall, Swift and Roberts, 1997 and Heath and Li, 2014 on multi-national comparisons).

Although the hypothesis from the endogenous mobility regimes theory has received much empirical support, the theory itself is not well developed at a conceptual level (Erikson and Goldthorpe, 1992). Why would a market economy and a nuclear family structure generate cross-temporal stability and cross-spatial similarity in relative mobility? A fuller account is found in the 'rational action theory' developed by Goldthorpe (2007). The main idea here is that in the competition for more advantaged positions and in avoidance of more disadvantaged positions, families in higher classes who tend to have a greater command of socio-economiccultural resources will use their superior resources to ensure that their children do well firstly in education and subsequently in occupational attainment. People in all classes can be expected to be rational actors in the sense that they tend to make well-considered decisions in order to maximise the chances of their children's educational and occupational success, but are differentially constrained by the limitations of their class situations. In the competition for more advantaged and in avoidance of more disadvantaged positions, people from higher class origins will thus have an advantage over those from lower family origins. The aggregate outcomes would be manifested in a difference in attainment fairly equivalent to the class disparity in condition (family origins), and such a difference is expected to persist unless powerful external forces intervene to modify the inequalities of condition, such as shown in the redistributive policies implemented under the social-democratic regimes in the Scandinavian countries (Jonsson and Mills, 1993). Recent research also shows that with the improvement of working-class conditions in the western countries, class disparities in educational attainment have declined (Breen et al., 2009).

Expectations of a Sino-British similarity in social fluidity are complicated in several ways. The redistributive policies by the government in the earlier years of the People's Republic of China (PRC) would lead us to expect greater equality in China than in Britain in the period, yet the rapid economic development and the attendant rising levels of disparity would lead us to expect greater inequality in China in the later period. The Gini coefficient in China jumped from 0.35 in 1980 to 0.45 in recent years, much higher than the 0.37 in the UK at the present time (UNDP, 2010: 26). Thus, even though China might have been more equal a few decades ago, it may have surpassed Britain in inequality in the more recent period.
Efforts at discerning inequality are further complicated by China's unique household registration system (hukou in Chinese). This system, initiated in 1955 to ease the population pressures in cities due to the rapid industrialisation, was institutionalised in the 1958 'Regulations on Household Registration', requiring all households to be registered with local authorities as either 'agricultural' or 'non-agricultural', the latter including 'state' and 'collective', hukou statuses. For half a century, the rural-urban division has acted like a barrier 'between heaven and earth' (Treiman, 2012). New-born babies follow mothers in hukou assignment, subjectingthe great majority of the Chinese people to 'agricultural' status. Rural hukou holders were destined as life-long agricultural workers (also called 'peasants', or nongmin in Chinese) even though their fathers were holding urban hukou status and doing non-agricultural work. In such cases downward mobility could occur, as observed by $\mathrm{Wu}$ and Treiman (2007). Obtaining upward hukou mobility was extremely difficult and only a very small fraction could hope to do this, usually by acquiring tertiary education (which was rare), or joining the army, getting promoted and returning to civilian life as an army officer. ${ }^{2}$ Yet, given the very large base of the rural sector, even a small portion attaining upward hukou mobility could make a big impact on the composition of the urban sector. Thus at any given point in time, one may find in the urban sector a large number of professional and managerial elites who are 'the best and brightest', having surmounted all the barriers in achieving upward hukou and class mobility, as well as the urban born, making the urban sector apparently highly fluid. ${ }^{3}$

Two other features are noteworthy here. Firstly, the last thirty years of reform and marketization have seen China becoming a 'world factory'. An estimated 260 million people of rural hukou status are currently working in cities as 'migrant workers'. In the process, a large proportion has become skilled workers,

2 After the end of the Cultural Revolution, the Government implemented firm-internal job replacement policies whereby rural grownup children could succeed their fathers working in the state or collective sector (called dingti and neizhao in Chinese, see Gong et al., 2012; Yu and Liu, 2004). We are grateful to an anonymous reviewer for pointing this out to us. It should be noted here that while these policies did enable upward hukou mobility and intergenerational counter mobility for a small proportion of rural people, they did not substantially change the urban-rural imbalance or hukou inequality. 3 In the last decade or so, hukou control has been gradually loosened in small- and medium-sized cities (below the level of prefecture) but in big, especially metropolitan, cities such as Beijing and Shanghai, there is still little sign of hukou opening up. 
technicians, professionals, managers or entrepreneurs even though they still have the formal rural hukou status. In the earlier period, men (husbands) tended to leave home to make money in cities, with women (wives) staying at home looking after children and parents and farming the land. In the more recent times, women and men were almost equally likely to be 'migrant workers'. About 160 million ( 60 per cent) of the migrant workers are the 'second new generation' born in the 1980s and 1990s many of whom were actually born and educated in cities and do not see their parents' home villages as their destination. Secondly, just as people of rural hukou may be doing 'non-agricultural' work, people engaged in agricultural work may have formal urban hukou status, such as those working on state farms. The implication of these features is that, for mobility research, we need to distinguish not only formal hukou statuses but also the actual work performed, namely, the occupational positions held by our respondents and their parents within each of the hukou sectors.

The hukou institution has several consequences for mobility research. Firstly, as its very purpose was to limit rural to urban migration and as the socioeconomic development in the city was at a much higher level than that in the countryside, we would expect more opportunities and higher rates of mobility in the urban sector. Secondly, as the rural sector has a very low starting point, we would expect rural people to have more upward and less downward mobility people starting from very low positions do not have much space to fall even lower. Thirdly, even though the objective mobility opportunities may be different, there may be no or little difference in relative mobility between the urban and the rural sectors given the relative constraints encountered by families in each sector. These are empirical matters to be investigated.

We now give a brief account of the key findings on mobility research in the two countries. A great deal of research has been conducted in Britain all showing pronounced class differences, yet no consensus seems to have been reached on the trends. Much debate is going on and one can discern three theses. The first is that of constant fluidity or trendless fluctuation, espoused by Goldthorpe and his colleagues (Goldthorpe, 1987; Goldthorpe and Jackson, 2007; Goldthorpe and Mills, 2004, 2008). The second is the thesis of declining mobility held by economists (Blanden et al., 2004). And the third is that of cautious optimism which fully acknowledges the marked inequalities but also finds some hopeful signs of social progress (Heath and Payne, 2000; Lambert, Prandy and Bottero, 2007; Devine and Li; 2013; Li and Devine; 2011, 2014; Li and Heath, 2014). It is also noted that evidence of a limited but significant increase in fluidity is also found in the work by Goldthorpe and Mills (2008: 94).

Mobility research in China is more limited. Earlier work tends to focus on the effects of state socialist policies. The elimination of the private ownership of means of production and the egalitarian programmes adopted in the first decades of the PRC were expected to break or at least weaken the links between origins and destinations. Some evidence was indeed found for this hypothesis. For instance, Parish (1981), using data collected in the mid-1970s on mainland immigrants in Hong Kong, found high levels of mobility, particularly during the Cultural Revolution period. Blau and Ruan (1990), using data collected in 1986, found greater fluidity in Tienjin than in the USA. While these studies showed some positive system effects, Cheng and Dai (1995) found no cohort changes in fluidity but greater inequality for women, which led them to reject claims of increasing openness under state socialism.

Although a great deal of research has been conducted in the two countries, no work is available that directly compares the mobility patterns between Britain and China. Yet from the theoretical positions outlined above, we may expect both similarities and differences. That is, we may expect higher rates of absolute mobility in Britain given its higher levels of economic development but increasing rates of mobility in China given its rapid pace of development in the last few decades, which would produce a convergence on absolute mobility. On the other hand, the higher levels of economic disparity in China would lead us to expect declining levels of social fluidity in the country with inequality catching up with or even surpassing that in Britain. In the following, we compare the patterns and trends of mobility in both absolute and relative domains in the two countries including, in China, a consideration of the hukou effects.

\section{Data and methods}

To address the questions outlined above, we use China General Social Survey (CGSS 2005, 2006, 2008, 2010) for China; General Household Survey (GHS 2005), British Household Panel Survey (BHPS 2006) and Understanding 
Society (USoc 2010) for Britain. ${ }^{4}$ They are all face-to-face interviews of people resident in private households in mainland China or Britain, with response rates ranging between 80 to 90 per cent.

We standardised the key variables needed for this research. With regard to class, we used a version of the EGP schema (Erikson, Goldthorpe and Portocarero, 1979) with six class categories: (1) higher and (2) lower (professional and managerial) salariat, (3) intermediate (routine non-manual and own-account), (4) supervisorial and technician; (5) skilled manual and (6) routine manual (for Britain) or agricultural workers (for China). ${ }^{5}$ We adopted the 'dominance approach' (Erikson, 1984) for origin class measured at respondent's age of 14-16, using whichever is higher of the parents' classes. Respondents' class was based on his or her current or last main job. The parental and respondent's class in the CGSS was converted from occupational titles and employment status via the International Standard Classification of Occupations (ISCO 1988, Ganzeboom and Treiman, 1996) and that for Britain was based on the National Statistics Socio-economic Classification (NSSeC, Rose and Pevalin, 2003). The schema has been thoroughly validated (Rose and Pevalin, 2003) and is widely used in Britain and Europe in mobility research, and also in the USA (Beller, 2009) and China (Cheng and Dai, 1995; Wu and Treiman, 2007; Liu, 2008; Chen, 2013; Li, 2013).

We coded hukou origin in China according to the respondent's mother's hukou status when the respondent was at age 14. China's socio-political changes could be divided into four periods: the planned economy (194965), the Cultural Revolution (1966-76), the dual-economic system (1977-92), and the 'socialist market economy'

4 The Chinese datasets are available at http://www.cssod.org/search. php?key=CGSS and the British datasets are available at http://ukdataservice.ac.uk/get-data.aspx. The CGSS is jointly conducted by the Survey Research Centre of the Hong Kong University of Science and Technology, and the Sociology Department of the People's University of China. The first CGSS survey was launched in 2003, followed annually or biennially. The 2003 cannot be used in this study as it contains only the urban sector. The CGSS 2005-10 series cover 28 provinces, autonomous regions, and municipalities in mainland China with the exception of Qinghai, Tibet and Ningxia. In the British part, we excluded data for Northern Ireland in the BHPS and the USoc as the GHS only covers Britain. Further details on the surveys can be found in the Technical Reports available in the websites above.

5 Prior analysis shows that for the oldest cohort in China, the sample sizes for parents in routine non-manual or own-account positions were too small for effective analysis, especially when men's and women's mobility was separately examined. As the overall market and work situation of the two groups was fairly similar, we grouped them into a single category and did that for both countries.
(1993 onwards). In view of this and for assessing trends in mobility, we adopt a semi-cohort approach by differentiating four birth cohorts: 1939-50, 1951-60, 1961-76, and 1977-85. Our oldest cohort will have mostly entered the labour market before 1966, the second during the Cultural Revolution, and so forth, corresponding to the major socio-political events that would have a major impact on people's life chances. As mobility in Britain is fairly stable, we adopt the same cohorts as for China. We confined the analysis to men and women aged 25-69 in the analysis. The effective sample sizes are 32,034 for China and 48,265 for Britain. ${ }^{6}$ We use a range of methods as appropriate for the task at hand and we shall explain them in the analysis section as needed.

\section{Analysis}

We present our findings in this section. We start with absolute mobility and then move to relative mobility. In both regards, we compare the patterns and trends in the two countries and try to see how they would fit the theoretical expectations.

\subsection{Absolute mobility}

To begin with, we look at the overall shapes of parents' and respondents' class in the two countries. For China, we also show the distributions by hukou origin. Table 1 shows the distributions and two summary indices: the dissimilarity and the net dissimilarity indices (DI and NDI). The DI shows the percentages of cases that would have to be reallocated to make the two distributions identical, hence the overall difference between the two distributions. As this index is insensitive to ordered data and to local changes in the data, and as it does not provide directional statements about the difference between origin and destination classes, we also use Lieberson's (1975)

6 Our analysis is, like other studies, subject to class biases such as selective mortality or non-response. It is known that people in poor socio-economic positions have higher mortality and lower response rates (see Goldthorpe, 1987, 2007 for discussion of the issues). To try to ameliorate the situation, we used the probability weights throughout the analysis as provided by the data collectors which are available in all datasets except CGSS 2010 where a weight of 1 is created for each case. 
Table 1 Distribution of family (F) and men's (M) and women's (W) class in China and Britain

\begin{tabular}{|c|c|c|c|c|c|c|c|c|c|}
\hline & \multicolumn{3}{|l|}{ All } & \multicolumn{3}{|c|}{ Urban hukou } & \multicolumn{3}{|c|}{ Rural hukou } \\
\hline & $\mathbf{F}$ & $\mathbf{M}$ & $\mathbf{w}$ & $\mathbf{F}$ & M & $\mathbf{W}$ & $\mathbf{F}$ & M & $\mathbf{W}$ \\
\hline \multicolumn{10}{|l|}{ China } \\
\hline 1 Higher salariat & 4 & 5 & 3 & 10 & 10 & 7 & 2 & 4 & 1 \\
\hline 2 Lower salariat & 7 & 9 & 8 & 15 & 15 & 16 & 3 & 6 & 4 \\
\hline 3 Intermediate & 6 & 12 & 13 & 14 & 19 & 24 & 3 & 9 & 9 \\
\hline 4 Supervisory/tech & 7 & 13 & 9 & 18 & 19 & 14 & 2 & 10 & 7 \\
\hline 5 Skilled manual & 9 & 25 & 20 & 22 & 32 & 30 & 4 & 22 & 16 \\
\hline 6 Agricultural & 67 & 37 & 47 & 21 & 4 & 9 & 86 & 49 & 63 \\
\hline DI & & 32 & 23 & & 15 & 18 & & 41 & 27 \\
\hline NDI & & 28 & 18 & & 9 & 6 & & 39 & 25 \\
\hline $\mathrm{N}$ & & 15,387 & 16,647 & & 5,415 & 5,638 & & 9,936 & 10,788 \\
\hline \multicolumn{10}{|l|}{ Britain } \\
\hline 1 Higher salariat & 13 & 20 & 9 & & & & & & \\
\hline 2 Lower salariat & 18 & 25 & 30 & & & & & & \\
\hline 3 Intermediate & 27 & 19 & 24 & & & & & & \\
\hline 4 Supervisory/tech & 10 & 12 & 6 & & & & & & \\
\hline 5 Skilled manual & 16 & 10 & 19 & & & & & & \\
\hline 6 Routine & 17 & 14 & 13 & & & & & & \\
\hline DI & & 14 & 15 & & & & & & \\
\hline NDI & & 12 & 6 & & & & & & \\
\hline $\mathrm{N}$ & & 21,930 & 26,335 & & & & & & \\
\hline
\end{tabular}

Note:

1. DI indicates overall differences between parental and respondent's class positions, and NDI indicates class advancement (see text for detail).

Source: China General Social Survey, General Household Survey, British Household Panel Survey and Understanding Society (see text for detail, the same below).

NDI as an indicator of class decline or advancement. ${ }^{7}$

Looking at the overall distributions, we can see that, as a developing country, China's salariat is much smaller in size than that in Britain, with only 11, 14 and 11 per cent of the parents, and male and female respondents being in such positions as compared with 31, 45 and 39 per cent in Britain. China has a big agricultural sector, with two thirds of the parents being agricultural workers, but the proportions dropped to 37 per cent for men and 47 per cent for women respondents. Chinese women were more likely to work in agriculture than men, by ten percentage points.

The rural-urban distinction reveals the pronounced hukou effects. A quarter of the urban families were in

7 The NDI is defined as NDxy $=\operatorname{pr}(\mathrm{X}>\mathrm{Y})-\operatorname{pr}(\mathrm{Y}>\mathrm{X})$ and further defined as

$$
\sum_{i=2}^{n} \chi_{i}\left(\sum_{j=1}^{n=i-1} \gamma_{j}\right)-\sum_{i=2}^{n} \gamma_{i}\left(\sum_{j=1}^{n=i-1} \chi_{j}\right)
$$

where $\mathrm{X}$ indicates the parental class and $\mathrm{Y}$ that of the respondent. It is noted here that following Lieberson (1975) we reversed the order in calculating the NDI with 1 referring to the lowest class and 6 to the higher salariat. The NDI is usually taken as ranging from -1 to 1 but the values are multiplied by 100 for ease of comparison with the DI scores. Positive values in the NDI indicate an advancement for the respondent's relative to the parental class. salariat positions, five times as high as their rural peers. 25 and 23 per cent of men and women from urban hukou origins were in the salariat as compared with only 10 and 5 per cent of their rural counterparts. By contrast, 86 per cent of the parents, nearly half of the men, and nearly two thirds of the women in the rural sector were agricultural workers.

The big agricultural base coupled with the large-scale rural to urban migration in the last thirty years would imply both a greater overall difference and a greater extent of social advancement in China than in Britain, as found in the DI and NDI indices. It is also the case that while in both countries men had greater advancement than women had, the gender gap is bigger in China than in Britain, by 10 and 6 points respectively. Because of the very low starting points, rural men and women gained much greater advancement than their urban counterparts in China and the gender gap in the rural sector is also bigger than in the urban sector in terms of both overall differences and class advancement.

To see changes over time, we look at parental and respondent's class distributions over the cohorts. Table 2 shows an upgrading occupational structure in both 
Table 2 Distribution of family (F) and respondent's (R) class by birth cohort in China and Britain

\begin{tabular}{|c|c|c|c|c|c|c|c|c|}
\hline & \multicolumn{2}{|c|}{$1939-50$} & \multicolumn{2}{|c|}{$1951-60$} & \multicolumn{2}{|c|}{$1961-76$} & \multicolumn{2}{|c|}{$1977-85$} \\
\hline & $\mathrm{F}$ & $\mathrm{R}$ & $\mathrm{F}$ & $\mathrm{R}$ & $\mathrm{F}$ & $\mathrm{R}$ & $\mathrm{F}$ & $\mathrm{R}$ \\
\hline \multicolumn{9}{|l|}{ China } \\
\hline 1 Higher salariat & 3 & 5 & 4 & 3 & 4 & 4 & 5 & 5 \\
\hline 2 Lower salariat & 4 & 8 & 6 & 7 & 8 & 8 & 9 & 12 \\
\hline 3 Intermediate & 4 & 9 & 5 & 10 & 6 & 14 & 10 & 16 \\
\hline 4 Supervisory/tech & 6 & 11 & 7 & 10 & 7 & 11 & 7 & 14 \\
\hline 5 Skilled manual & 8 & 15 & 10 & 21 & 9 & 24 & 10 & 27 \\
\hline 6 Agricultural & 76 & 51 & 69 & 49 & 66 & 40 & 59 & 26 \\
\hline DI & & 27 & & 21 & & 28 & & 33 \\
\hline NDI & & 27 & & 17 & & 22 & & 27 \\
\hline $\mathrm{N}$ & & 5,685 & & 7,328 & & 14,125 & & 4,896 \\
\hline \multicolumn{9}{|l|}{ Britain } \\
\hline 1 Higher salariat & 8 & 11 & 12 & 14 & 15 & 16 & 17 & 14 \\
\hline 2 Lower salariat & 12 & 23 & 15 & 28 & 20 & 30 & 25 & 29 \\
\hline 3 Intermediate & 24 & 24 & 26 & 22 & 28 & 21 & 28 & 20 \\
\hline 4 Supervisory/tech & 13 & 9 & 11 & 9 & 10 & 8 & 8 & 9 \\
\hline 5 Skilled manual & 20 & 16 & 18 & 14 & 14 & 13 & 12 & 16 \\
\hline 6 Routine & 23 & 18 & 19 & 14 & 14 & 12 & 10 & 11 \\
\hline DI & & 14 & & 15 & & 11 & & 11 \\
\hline DNI & & 15 & & 14 & & 8 & & -4 \\
\hline $\mathrm{N}$ & & 10,850 & & 10,596 & & 19,519 & & 7,300 \\
\hline
\end{tabular}

countries, and that for parents' and respondents' classes alike. In China, the proportions found in agricultural work declined from 76 to 59 per cent for parents and from 51 to 26 per cent for respondents. People leaving agricultural work tend to move to manual-industrial or service-sector jobs in China. In Britain, the working class continued to contract whilst the salariat classes continued to grow between the first and the third cohorts (some members in the youngest cohort had not reached 'occupational maturity' yet, defined as age 35, see Goldthorpe, 1987: 52). Over the successive cohorts, a smaller proportion was found in working-class and even intermediate positions, and a larger proportion was found in the salariat, again for parents' and respondents' positions alike.

The summary indices show a clear fall in both DI and NDI values for the second cohort in China, namely, those who were born between 1951 and 1960 and who entered the labour market during the Cultural Revolution period. That was a chaotic period in China with economic stagnation and political turmoil, which clearly limited people's chances for social advancement, as compared with the earlier or the later cohorts. Other scholars have also taken note of this (Deng and Treiman, 1997) and we shall have more evidence on this in the following discussion. For present purposes, what is worth noting is that social advancement suffered most for this cohort and did not fully recover until the reforms were in full swing, namely, for the youngest cohort. In Britain, occupational upgrading slowed down and slackened to a halt in the more recent times, with notable declines in class advancement over the cohorts, echoing findings by Goldthorpe and Jackson (2007), and Goldthorpe and Mills (2008).

While the foregoing reveals important overall differences in class distributions and in class advancement between the two countries, we need a fuller understanding by decomposing absolute mobility into its components, that is, into rates of total, upward, downward and horizontal mobility. Table 3 shows the overall outflow rates. The first striking feature we find in the table is that immobility rates are nearly twice as high among the top two classes in Britain as in China but the opposite is true among the bottom three classes. Downward mobility from the salariat origins to the manual destinations is nearly twice as high in China as in Britain. The 'stickiness' operates at different ends of the class structure in the two countries.

The shades in Table 3 indicate different kinds of mobility: immobility on the diagonal, and mobility differentiated into upward, downward and horizontal aspects (lighter, darker and no shades respectively). Had we presented the data in relative frequency, we could have calculated the component rates directly, which we show in Table 4 where results of statistical tests are also shown for the differences in the rates between men and women, between younger cohorts and the oldest one and, for China, between rural and urban hukou origins. 
Table 3 Class distribution (percentage by row)

\begin{tabular}{|c|c|c|c|c|c|c|c|}
\hline & 1 & 2 & 3 & 4 & 5 & 6 & (N) \\
\hline \multicolumn{8}{|l|}{ China } \\
\hline 1 Higher salariat & 14.3 & 18.6 & 20.6 & 11.9 & 22.2 & 12.4 & 1,640 \\
\hline 2 Lower salariat & 9.8 & 19.3 & 18.9 & 12.5 & 24.0 & 15.7 & 2,532 \\
\hline 3 Intermediate & 7.6 & 14.3 & 26.7 & 12.9 & 28.0 & 10.5 & 2,104 \\
\hline 4 Supervisory/tech & 5.6 & 11.4 & 18.8 & 23.0 & 31.8 & 9.5 & 2,622 \\
\hline 5 Skilled manual & 5.4 & 11.2 & 17.4 & 17.2 & 37.6 & 11.2 & 3,433 \\
\hline 6 Agricultural & 2.2 & 5.2 & 8.7 & 8.5 & 18.6 & 56.7 & 19,703 \\
\hline \multicolumn{8}{|l|}{ Britain } \\
\hline 1 Higher salariat & 28.2 & 35.9 & 18.9 & 4.5 & 6.7 & 5.7 & 6,033 \\
\hline 2 Lower salariat & 19.7 & 36.2 & 20.1 & 6.5 & 10.3 & 7.3 & 8,615 \\
\hline 3 Intermediate & 13.6 & 27.5 & 25.1 & 8.4 & 13.7 & 11.8 & 13,074 \\
\hline 4 Supervisory/tech & 10.9 & 24.7 & 22.6 & 10.7 & 15.8 & 15.3 & 4,978 \\
\hline 5 Skilled manual & 8.2 & 21.6 & 20.7 & 10.7 & 19.5 & 19.4 & 7,540 \\
\hline 6 Routine & 7.1 & 19.1 & 20.1 & 11.2 & 18.6 & 23.9 & 8,025 \\
\hline
\end{tabular}

Table 4 Summary statistics of absolute mobility rates in China and Britain

\begin{tabular}{|c|c|c|c|c|}
\hline & Total mobility & Upward mobility & Downward mobility & Horizontal mobility \\
\hline \multicolumn{5}{|l|}{ China } \\
\hline All & 57.8 & 37.2 & 13.8 & 6.8 \\
\hline \multicolumn{5}{|l|}{ Gender } \\
\hline Men & 61.4 & 42.1 & 12.9 & 6.5 \\
\hline Women & $54.4^{\star \star \star}$ & $32.6^{\star \star \star}$ & 14.6 & 7.2 \\
\hline \multicolumn{5}{|l|}{ Cohort } \\
\hline $1939 / 50$ & 51.9 & 37.9 & 9.1 & 4.9 \\
\hline $1951 / 60$ & 51.3 & $31.1^{\star \star \star}$ & $14.1^{\star \star \star}$ & 6.1 \\
\hline $1960 / 76$ & $59.4^{\star \star \star}$ & 37.4 & $14.7^{\star \star \star}$ & $7.3^{\star \star \star}$ \\
\hline $1977 / 85$ & $69.8^{\star \star \star}$ & $45.0^{\star \star \star}$ & $15.9^{\star \star \star}$ & $8.8^{\star \star \star}$ \\
\hline \multicolumn{5}{|l|}{ Hukou } \\
\hline Urban & 73.2 & 32.0 & 25.5 & 15.7 \\
\hline Rural & $49.4^{\star \star \star}$ & $39.9^{\star \star \star}$ & $7.4^{\star \star \star}$ & $2.0^{\star \star \star}$ \\
\hline \multicolumn{5}{|l|}{ Britain } \\
\hline All & 75.3 & 30.1 & 26.1 & 19.1 \\
\hline \multicolumn{5}{|l|}{ Gender } \\
\hline Men & 75.6 & 33.4 & 23.4 & 18.8 \\
\hline Women & 75.0 & $27.4^{\star \star \star}$ & $28.3^{\star \star \star}$ & 19.4 \\
\hline \multicolumn{5}{|l|}{ Cohort } \\
\hline $1939 / 50$ & 76.3 & 34.2 & 24.7 & 17.5 \\
\hline $1951 / 60$ & 75.9 & 33.1 & 24.0 & 18.9 \\
\hline $1960 / 76$ & $75.2^{\star \star}$ & $28.8^{\star \star \star}$ & 26.3 & $20.1^{\star \star \star}$ \\
\hline $1977 / 85$ & $73.1^{\star \star \star}$ & $23.3^{\star \star \star}$ & $30.4^{\star \star \star}$ & $19.4^{\star \star \star}$ \\
\hline
\end{tabular}

Notes:

1. Significance tests are conducted, with men, 1939/50 and in China's case, urban as reference groups.

2. * $p<0.05 ;{ }^{* *} p<0.01 ;{ }^{* *} p<0.001$. 
At the most general level, we find a higher rate of total mobility in Britain than that in China: 75.3 and 57.8 per cent respectively. Although the overall mobility rate is lower, China has a higher rate of upward mobility, at 37.2 per cent, as compared with 30.1 per cent in Britain. With regard to gender differences, women in both countries have significantly lower upward mobility than their male counterparts, by 9.5 percentage points in China and 6 points in Britain. As for to cohort differences, we noted earlier a decline in class advancement for people who entered the labour market during the Cultural Revolution, and here we find a significant fall in upward mobility and a significant rise in downward mobility for the cohort as compared with the preceding one. There is a general increase in total and upward mobility rates over the cohorts. As to the former, the rate rose from the 51.9 per cent in the oldest cohort to 69.8 per cent in the youngest cohort while the corresponding figures for Britain fell slightly (from 76.3 to 73.1 per cent), suggesting a path of convergence as expected from the modernization theory. The highest rate of upward mobility in China was found for the youngest cohort, at 45 per cent, which is nearly twice as high as that for Britain (23.3 per cent). Finally in this regard, we find that people of rural hukou origins had lower rates of total mobility, higher rates of upward mobility, and lower rates of downward mobility than their urban peers, all being significant and confirming our expectations.

To sum up on absolute mobility, we found a more developed class structure in Britain, a higher level of class advancement in China, a convergence in total mobility between the two countries and, above all, very limited mobility opportunities for rural people in China. These features reflect the contextual differences but not necessarily the fluidity levels. It is to this latter respect that we now turn our attention.

\subsection{Relative mobility}

As noted earlier, mobility research is more concerned with relative mobility, that is, the competition of people from different origin classes for one rather than another destination class, which is expressed in terms of odds ratios. If origin and destination classes were completely unrelated to one another, there would be equal mobility chances, or an odds ratio of 1 . The closer the odds ratio is to 1 , the weaker the association and the greater the social equality while the further away the odds ratio rises above 1 , the stronger the association and the greater the inequality. Relative mobility thus taps the net association between origins and destinations, independent of the structural changes as reflected in the marginal distributions.

Two statistical models are usually used in relative mobility analysis: loglinear and uniform difference (UNIDIFF) models (Erikson and Goldthorpe, 1992). The former is subdivided into a baseline (conditional independence) and a constant/common social fluidity (CnSF/CmSF) model. ${ }^{8}$ The baseline model assumes that the distributions of both origins and destinations vary by cohort but there is no association between them. In other words, all the odds ratios or relative chances defining origin and destination classes are equal at a value of one. The CnSF model allows for the latter association but does not allow for the three-way association, which would be a saturated model. The UNIDIFF model is a variant of the CnSF model which further allows for a uniform movement for the coefficient of one cohort to move above or below that of the other. In the present analysis, we use the oldest cohort as the reference group. Thus the further away the coefficients for the younger cohorts are above that for the oldest cohort, the more unequal the society is becoming, and vice versa. (We also conducted analysis on common social fluidity, CmSF, between men and women, between urban and rural origins in China, and between the two countries as will be reported below.)

Before proceeding to statistical models, it is necessary to see the extent of social inequality in the two countries. In Table 5 we show the symmetrical odds ratios. Take the first row in the table. In the first cell, we see that Chinese men from higher salariat origins are 1.82 times as likely to find themselves in higher rather than lower salariat positions as men from lower salariat origins to be in higher rather than lower salariat positions. The corresponding figure for Britain is 1.39 as shown in the cell below, with no significant difference between the two odds ratios. As we move to the right, we see increasing odds ratios and find, in the top-right corner of the table on the competition between the top and the bottom origin and destination classes, an odds ratio of 21.06 for Chinese men and 16.71 for British men. In the lower part of the table are data for women where in the bottom-left corner

8 The models can be written as:

1: Baseline model (conditional independence)

$\log \mathrm{F}_{i j k}=\mu+\lambda_{i}^{\mathrm{O}}+\lambda_{j}^{\mathrm{D}}+\lambda_{k}^{\mathrm{Y}}+\lambda_{i k}{ }^{\mathrm{OY}}+\lambda_{j k}^{\mathrm{DY}}$

2: Constant social fluidity model (CnSF)

$\log \mathrm{F}_{i j k}=\mu+\lambda_{i}^{\mathrm{O}}+\lambda_{j}^{\mathrm{D}}+\lambda_{k}^{\mathrm{Y}}+\lambda_{i k}^{\mathrm{OY}}+\lambda_{j k}^{\mathrm{DY}}+\lambda_{i j}{ }^{\mathrm{OD}}$

3: Uniform difference (UNIDIFF) model

$\log \mathrm{F}_{i j k}=\mu+\lambda_{i}^{\mathrm{O}}+\lambda_{j}^{\mathrm{D}}+\lambda_{k}^{\mathrm{Y}}+\lambda_{i k}^{\mathrm{OY}}+\lambda_{j k}^{\mathrm{DY}}+\lambda_{i j}^{\mathrm{OD}}+\beta_{k} \mathrm{X}_{i j}$

where $\mathrm{O}$ stands for class origin, $\mathrm{D}$ for class destination, $\mathrm{Y}$ for cohort. In the UNIDIFF model, Xij indicates the general pattern of the origin-destination association, and $\beta k$ the direction and the relative strength of this association specific to the oldest cohort. 
Table 5 Symmetrical odds ratios for mobility tables: upper figure in each pair for China and lower figure in each pair for Britain (upper right matrices for men and lower left matrices for women)

\begin{tabular}{|c|c|c|c|c|c|c|}
\hline \multirow[b]{2}{*}{ Class } & \multicolumn{6}{|c|}{ Class } \\
\hline & 1 & 2 & 3 & 4 & 5 & 6 \\
\hline \multirow[t]{2}{*}{1} & & 1.82 & 3.12 & 5.10 & 5.20 & 21.06 \\
\hline & & 1.39 & 3.34 & 5.41 & 10.95 & 16.71 \\
\hline \multirow[t]{2}{*}{2} & $1.25^{\star}$ & & 2.13 & 2.92 & 2.40 & 12.42 \\
\hline & 1.53 & & 1.78 & 2.41 & 3.33 & 6.15 \\
\hline \multirow[t]{2}{*}{3} & 1.95 & 1.75 & & 2.94 & 2.04 & 16.87 \\
\hline & 2.42 & 1.54 & & 1.46 & 1.94 & 2.45 \\
\hline \multirow[t]{2}{*}{4} & 4.99 & 3.28 & 2.24 & & 1.69 & 18.43 \\
\hline & 7.90 & 2.16 & 1.28 & & 1.50 & 1.64 \\
\hline \multirow[t]{2}{*}{5} & 3.81 & 2.96 & 2.06 & 1.46 & & 12.40 \\
\hline & 10.86 & 3.06 & 1.58 & 0.90 * & & 1.22 \\
\hline \multirow[t]{2}{*}{6} & 54.34 & 16.09 & 16.78 & 14.68 & 9.17 & \\
\hline & 17.76 & 6.23 & 2.96 & $1.24^{\star}$ & 1.39 & \\
\hline
\end{tabular}

Notes:

1. All odds ratios are significant at the 0.05 level or above except those with *.

2. Pairs of odds ratios which are significantly different at the 0.05 level or above are indicated in emboldened figures in the British part of the data.

we find a staggering ratio of 54.34 for Chinese and that of 17.76 for British women. Such disparities are the very opposite of any ideal of equality. Another salient feature in the table concerns the substantially and significantly larger odds ratios between the non-agricultural and the agricultural sectors in China than between the higher and the lower classes in Britain, for men and women alike, as shown in the emboldened figures, a clear indication of the institutional barrier against mobility in China.

The symmetrical ratios reveal the extent of inequality but do not clearly show the trends of fluidity. To address the latter issue, we proceed to loglinear and UNIDIFF modelling. Table 6 shows the statistics of the conditional independence, constant social fluidity (CnSF) and the UNIDIFF models fitted to the Chinese and the British data (pooling men and women together), with the cohort as the trend indicator in the UNIDIFF part. Here we find that the $\mathrm{p}$ values for the CnSF and the UNIDIFF models are all below 5 per cent in the two countries, indicating an inadequate fit to the data. However, in China's, albeit not in Britain's, case, the UNIDIFF model does provide a significant improvement in fit over the CnSF models $(\mathrm{p}=0.02)$. This suggests significant changes in fluidity were taking place in China.

To see how the fluidity patterns were unfolding, we show, in Figure 1, the parameter estimates (in terms of log odds) under the UNIDIFF models together with the 95 per cent confidence intervals. To see the changes more clearly, we show four panels: the overall trends of fluidity between the two countries, trends by hukou origins in China (and in

Table 6 Fit statistics for the conditional independence (cond. ind.), constant social fluidity (CnSF) and UNIDIFF models fitted to mobility tables

\begin{tabular}{|c|c|c|c|c|c|c|}
\hline Model & $\mathbf{G}^{2}$ & Df & $\mathbf{p}$ & $\mathbf{r G}^{2}$ & $\Delta$ & BIC \\
\hline \multicolumn{7}{|c|}{ China $(N=32,034)$} \\
\hline 1. Cond. ind. & 7234.4 & 100 & 0.00 & -- & 19.3 & 6197.0 \\
\hline 2. CnSF & 214.5 & 75 & 0.00 & 97.0 & 2.3 & -563.6 \\
\hline 3. UNIDIFF & 205.0 & 72 & 0.00 & 97.2 & 2.3 & -541.9 \\
\hline 2. - 3 . & 9.5 & 3 & 0.02 & & & \\
\hline \multicolumn{7}{|c|}{ Britain $(\mathrm{N}=48,265)$} \\
\hline 1. Cond. ind. & 4417.0 & 100 & 0.00 & -- & 11.5 & 3338.5 \\
\hline 2. $\mathrm{CnSF}$ & 101.4 & 75 & 0.02 & 97.7 & 1.7 & -707.5 \\
\hline 3. UNIDIFF & 97.3 & 72 & 0.03 & 97.8 & 1.6 & -679.2 \\
\hline $2 .-3$ & 4.1 & 3 & 0.25 & & & \\
\hline
\end{tabular}

Note: $\Delta$ refers to dissimilarity index or percentage of cases misclassified. 
Panel 1: China and Britain (all)

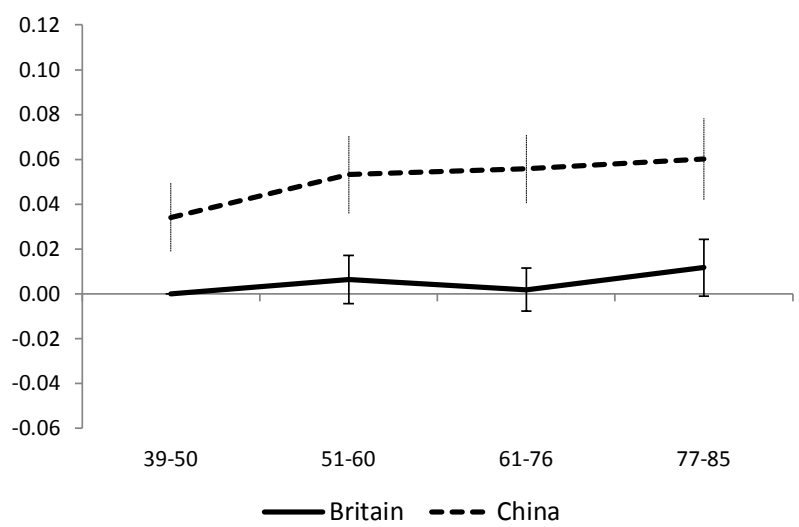

Panel 3: China and Britain: men

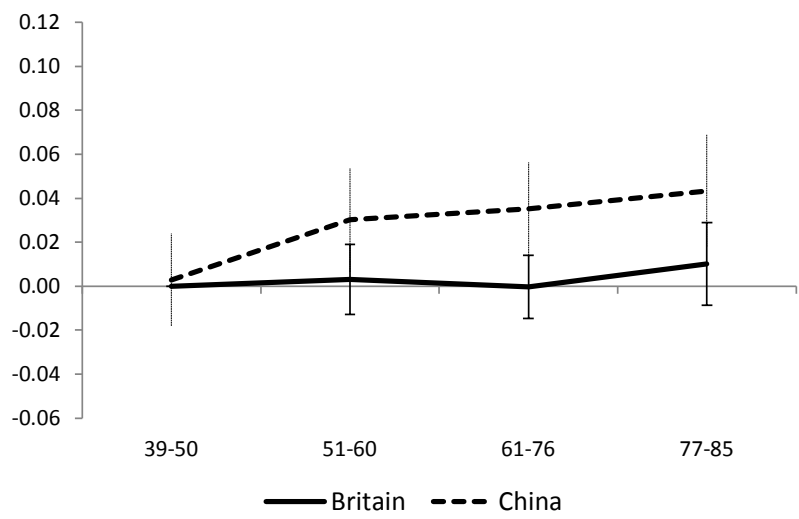

Panel 2: Hukou in China

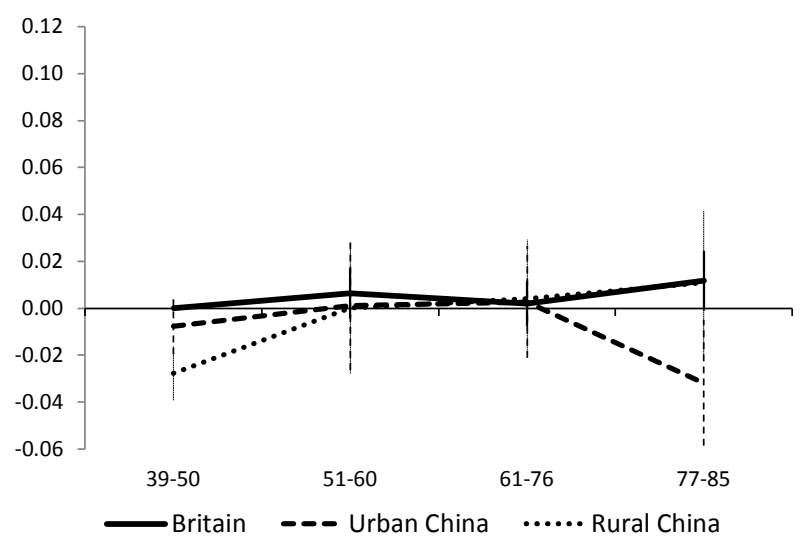

Panel 4: China and Britain: women

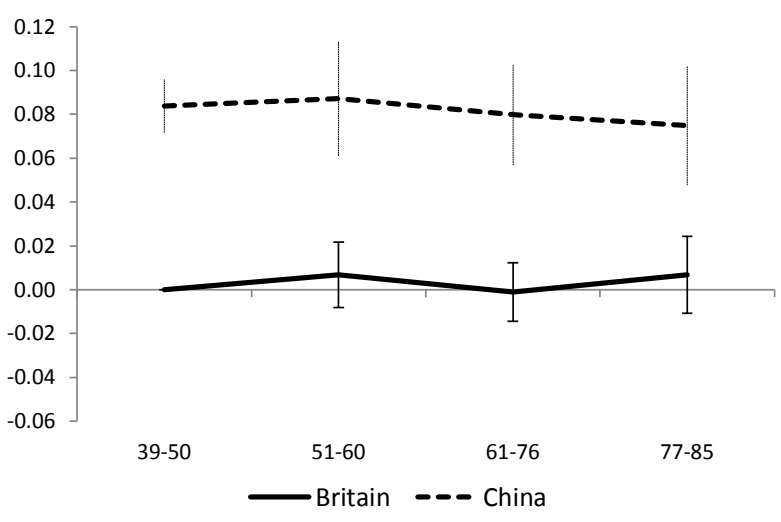

Figure 1: Trends of social fluidity in China and Britain

comparison with Britain), and trends for men and women separately in the two countries.

Panel 1 shows that, overall, inequality was greater in China. What is more, while the pattern was generally stable in Britain, the line for China was on the rise, indicating a substantial increase in inequality over the cohorts. There is no evidence of a general or converging similarity in the levels of fluidity between the two countries as expected from the modernisation or the 'endogenous mobility regimes' theory. The complementary evidence in Panels 3 and 4 shows that the widening gaps in inequality was due to the increasing rigidity in Chinese men's mobility as compared with British men, and the consistently higher inequality experienced by Chinese women relative to British women. Chinese women suffered the greatest disadvantages.

While the data in Panels 1, 3 and 4 did not meet the expectations from the endogenous mobility regimes theory nor provide evidence of a positive effect of state socialism, data in Panel 2 do render some support for the former. Here we find that the lines for both rural and urban sectors in China are at a level generally similar to or somewhat below that for Britain. Looking more closely, we find rising inequality for people of rural hukou origins in China. The increasing mobility opportunities created by the reforms seems to have led to a greater inequality in the rural sector. By contrast, for the youngest cohort from the urban hukou origins, there is a notable and significant increase in fluidity, which can be viewed as a consequence of greater competition both due to the marketization process within the urban sector and arising from the constant inflow of rural migrants. For the older cohorts, having an urban hukou entailed entitlement to life-long employment with various benefits guaranteed by the state. For the youngest cohort of urbanites, job assignment was something of the past. A competitive market would entail both upward and downward mobility. ${ }^{9}$

9 As downward mobility is typically higher among young people, it is reasonable to believe that a substantial proportion among them will achieve counter-mobility in the course of their career development (see Goldthorpe, 1987: 57 for evidence). 
To sum up on relative mobility, we did not find evidence in support of claims of a similar level of fluidity in the two countries as expected from the endogenous mobility regimes theory nor that of a converging path from the modernisation theory. Rather, we found a higher and rising level of inequality in China. However, separating the hukou sectors, we did find similar fluidity profiles which were also comparable to that in Britain.

\subsection{Access to the salariat}

In the final part of this section, we look at access to the professional-managerial salariat. The results are shown in Table 7 where Models 1 and 2 are comparable in the two countries and models 3 and 4 are China-specific. We report the results in terms of average marginal effects (AME) derived from logit regressions for ease of exposition. The coefficients pertain to percentage point differences in the net effects. Also shown are results of statistical tests of pair-wise comparisons where significant differences are listed in China's part.

Model 1 in Table 7 shows that family class, gender and cohort all have a significant net effect, with a clear and smooth class gradient in both countries. As Britain has a much larger salariat, people from all class backgrounds, gender statuses and cohorts in China were less likely than their British counterparts to find themselves in the salariat, and the cross-country differences are all significant except for those from lower salariat families. ${ }^{10}$ In Model 2 where educational qualifications are added, we find that the origin effects were all reduced but did not disappear. Gender effects in China became non-significant. Chinese women were on the whole less educated than Chinese men but among those with similar levels of education, no gender penalty was evident, unlike the case in Britain. Again due to the smaller size of the salariat, people at similar levels of education in China were significantly less likely than their British counterparts to have a salariat job. Once the effects of the other factors were taken into account, there are no significant class differences between the two countries but such differences remain highly significant within each country.

In Models 3 and 4 we focus on China. Other things being equal, we find that people of rural hukou origins

10 Other things being equal, the second cohort in China were $5 \%$ less likely to have a salariat job than the oldest cohort, which shows a similar extent to the decline in educational attainment found in Deng and Treiman (1997).

Table 7 Average marginal effects on access to the salariat

\begin{tabular}{|c|c|c|c|c|c|c|}
\hline & \multicolumn{4}{|c|}{ China } & \multicolumn{2}{|c|}{ Britain } \\
\hline & Mode 1 & Model 2 & Model3 & Mode 4 & Model 1 & Model2 \\
\hline \multicolumn{7}{|l|}{ Class (H salariat=ref) } \\
\hline Lower salariat & $-0.038^{\star}$ & -0.006 & -0.024 & -0.006 & $-0.082^{\star \star \star}$ & $-0.020^{\star}$ \\
\hline Intermediate & $-0.118^{\star \star \star}$ & $-0.041^{\star \star \star}$ & 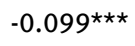 & $-0.043^{\star \star \star}$ & $-0.227^{\star \star \star}$ & $-0.094^{\star \star \star}$ \\
\hline Supervisory/tech & $-0.163^{\star \star \star}$ & $-0.059 * \star \star$ & $-0.138^{\star \star \star}$ & $-0.060 \star \star \star$ & $-0.279 * \star \star$ & $-0.106^{\star \star \star}$ \\
\hline Skilled manual & $-0.166^{\star \star \star}$ & $-0.044^{\star \star \star}$ & $-0.135^{\star \star \star}$ & $-0.048 * \star \star$ & $-0.334^{\star \star \star}$ & $-0.130^{\star \star \star}$ \\
\hline Agricultural/Routine & $-0.258^{\star \star \star}$ & $-0.059 * \star \star *$ & 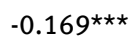 & $-0.061 * \star \star$ & $-0.370 * \star \star$ & $-0.154^{\star \star \star}$ \\
\hline \multicolumn{7}{|l|}{ Gender (female=ref) } \\
\hline Male & $0.036 * \star \star$ & 0.006 & $0.036 * \star \star$ & 0.006 & $0.053^{\star \star \star}$ & $0.052^{\star \star \star}$ \\
\hline \multicolumn{7}{|l|}{ Cohort (1939-50=ref) } \\
\hline $1951-60$ & $-0.051^{\star \star \star}$ & $-0.085^{\star \star \star}$ & $-0.046^{\star \star \star}$ & $-0.082^{\star \star \star}$ & $0.062^{\star \star \star}$ & 0.007 \\
\hline $1960-76$ & 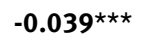 & $-0.108^{\star \star \star}$ & $-0.032^{\star \star \star}$ & $-0.104^{\star \star \star}$ & $0.075^{\star \star \star}$ & -0.005 \\
\hline \multicolumn{7}{|l|}{ Hukou (urban=ref) } \\
\hline Rural & & - & $-0.096 * \star \star$ & -0.004 & - & - \\
\hline \multicolumn{7}{|l|}{ Education (tertiary=ref) } \\
\hline High secondary & & $-0.342 * \star \star$ & & $-0.371^{\star \star \star}$ & & $-0.248^{\star \star \star}$ \\
\hline Lower secondary & & 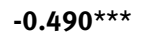 & & $-0.523^{\star \star \star}$ & & 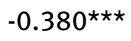 \\
\hline Primary/none & & $-0.540 \star \star \star$ & & $-0.570 \star \star \star$ & & $-0.518^{\star \star \star}$ \\
\hline $\mathrm{N}$ & 32,034 & 32,012 & 31,977 & 31,955 & 47,600 & 46,183 \\
\hline
\end{tabular}

Notes: The coefficients on education in Model 4 (for China) refer to the hukou*education interaction.

Significant differences (at $5 \%$ or above) between corresponding categories in China and Britain are shown in emboldened figures.

${ }^{\star} p<0.05,{ }^{\star *} p<0.01,{ }^{\star * \star} p<0.001$. 
are 9.6 per cent less likely to have a salariat job. While a very small proportion of the rural proportion (4.4 per cent in our sample) could obtain higher education, the vast majority were less fortunate, with 83 per cent having only lower secondary education or below. In Model 4 we find that rural people at higher secondary, lower secondary and primary levels of education were much behind their urban peers in gaining a foothold in the salariat, by 37 , 52 and 57 percentage points. The differences are all highly significant, giving compelling evidence of institutional (hukou) penalty against rural people in contemporary China.

\section{Discussion and Conclusion}

In this paper, we have sought to make a contribution to understanding social mobility in contemporary Chinese and British societies. We used a range of data sources in the two countries to address the questions.

Our main questions centred on whether social mobility in China would increase with the economic development in the last few decades so as to parallel that in Britain as expected by modernisation or endogenous mobility regimes theories, whether state socialist policies would engender greater equality in China in the earlier period but the faster pace of economic disparity would result in greater inequality than found in Britain in the more recent period, and how China's unique institutional (hukou) barrier hampered the mobility chances for the vast majority of the Chinese people in the countryside.

To recap, we found, with regard to absolute mobility, that the much lower starting point facilitated a higher rate of class advancement and upward mobility in China, that total mobility rates exhibited strong signs of convergence in the two countries, and that there were marked class and gender differences in both countries. As for relative mobility, we found greater inequality in China at the overall level, which can be decomposed into persistently greater inequality experienced by Chinese women, and increasing inequality by Chinese men relative to their British peers. Expectations from the endogenous mobility regimes theory found support when the fluidity levels of the rural and the urban sectors in China were separately analysed and juxtaposed with the British data. The rural people in China were doubly disadvantaged: they were much less likely than urbanites to have education in the first place; and even when they had similar levels of education, they were still much behind their urban peers to have a salariat job.
In sum, our analysis shows greater inequality in China than in Britain resulting mostly from China's institutional barrier, with Chinese women having greatest disadvantages. The findings also prompt us to consider other issues which we have not been able to address in this paper due to space limit. Firstly, the socio-economic development in China is proceeding at a very fast pace, such as the expansion of higher education that started in 1998 and the urbanisation programme that started in 2008 loosening hukou control in small and medium cities. Around 30 million students are currently studying in China's higher learning institutions including a substantial number from rural origins who are likely to have greater upward mobility than their parental generation. An even larger proportion of young people from rural backgrounds are entering cities as the 'new generation of migrant workers'. The hukou barrier will lose some of its impacts for them. The mobility patterns of the new cohorts of graduates and migrant workers from rural origins await analysis upon the release of new data sources.

Secondly, our analysis only painted a broad-brush picture. As China is a much bigger country than Britain, the geographic variations in the mobility effects in both absolute and relative domains merit further investigation. The contextual effects can be further dissected into the current status of socio-economic development and the deprivation levels in people's formative years, both of which may have important impacts on people's mobility chances.

Thirdly, our measurement of class may have underestimated the true levels of social inequality in the two societies. Whilst the class schema adopted for the analysis is widely used in mobility research, the categorical nature of the schema means that we have not been able to look at the differences within the classes. For example, 45 and 39 per cent of men and women in the British sample are in the salariat. Do upwardly mobile workingclass women concentrate in the lower salariat? Future analysis could complement or enrich the current work by using continuous variables such as the International Socio-Economic Index (ISEI) where other techniques such as structural equation modelling could be employed to investigate the processes of social mobility.

Overall, while our analysis has made a useful contribution to understanding social mobility in the two countries, it has also revealed more issues to be explored. As the two societies are changing rapidly and as more datasets are becoming available, there will be more opportunities for students of sociology to analyse the emerging social inequality in the two countries. 
Acknowledgement: We are grateful to the Economic and Social Research Council (ESRC) in Britain for funding the project 'Social mobility and social capital in China and Britain, a comparative study' (ES/I035168/1) which is link-funded by the National Natural Science Foundation of China (NSFC) (71010090) where the first author is the PI. We are also grateful to Professors Richard Breen and Tak Wing Chan, and other attendants at the RC28 for their helpful comments on a previous version of the paper, and to the Editors and the two anonymous reviewers for the suggestions which have benefited us in the revision. We alone are responsible for any errors that may exist in the paper.

\section{Reference}

Atkinson, W. (2007a) 'Anthony Giddens as Adversary of Class Analysis'. Sociology, 41(3): 533-549.

Atkinson, W. (2007b) 'Beck, individualization and the death of class: a critique'. British Journal of Sociology, 58(3): 349-366.

Atkinson, W. (2008) 'Not all that was solid has melted into air (or liquid): a critique of Bauman on individualisation and class in liquid modernity'. The Sociological Review (56)1: 1-17.

Bauman, Z. (1998) Globalisation: the human consequences, Oxford: Blackwells.

Beck, U. and E. Beck-Gernsheim (2002) Individualization: institutionalized individualism and its social and political consequences, London: Sage.

Beller, E. (2009) 'Bringing Intergenerational Social Mobility Research into the Twenty-first Century: Why Mothers Matter', American Sociological Review, 74: 507-528.

Blanden, J., A. Goodman, P. Gregg, and S. Machin (2004) 'Changes in Intergenerational Income Mobility in Britain'. In Corak, M. (ed.) Generational Income Mobility in North America and Europe, pp: 122-146. Cambridge: Cambridge University Press.

Blau, P. and O. Duncan (1967) The American Occupational Structure. New York: John Wiley Press.

Blau, P. and D. Ruan (1990) 'Inequality of Opportunity in Urban China and America'. Research in Social Stratification and Mobility, 9: 3-32.

Breen, R. (ed.) (2004) Social Mobility in Europe. Oxford: Oxford University Press.

Breen, R., R. Luijkx, W. Müller and R. Pollak (2009) ‘Non-Persistent Inequality in Educational Attainment: Evidence from Eight European Countries'. American Journal of Sociology, 114(5): 1475-1521.

Bukodi, E. and J. H. Goldthorpe (2010) 'Market versus Meritocracy: Hungary as a critical case', European Sociological Review, 26(6): 655-674.

Chan, T.W. and Goldthorpe, J.H. (2005). The social stratification of theatre, dance and cinema attendance. Cultural Trends, 14(3): 193-212.

Chen, M. (2013) 'Intergenerational mobility in contemporary China'. Chinese Sociological Review, 45(4): 29-53.

Cheng, Y. and J. Dai (1995) 'Intergenerational Mobility in Modern China'. European Sociological Review, 11: 17-36.
Deng, Z. and D. Treiman (1997) 'The Impact of the Cultural Revolution on Trends in Educational Attainment in the People's Republic of China'. American Journal of Sociology, 103: 391-428.

Devine, F. and Y. Li (2013) 'The changing relationship between origins, education and destinations in the 1990s and 2000s'. British Journal of Sociology of Education, 34(5-6): 766-791.

Erikson, R. (1984) 'Social Class of Men, Women and Families'. Sociology, 18: 500-514.

Erikson, R. and J. H. Goldthorpe (1992) The Constant Flux: A Study of Social Mobility in Industrial Societies. Oxford: Clarendon.

Erikson, R., J. H. Goldthorpe and L. Portocarero (1979) 'Intergenerational Class Mobility in Three Western European Societies'. British Journal of Sociology, 30(4): 415-441.

Featherman, D., F. Jones and R. Hauser (1975) 'Assumptions of Social Mobility Research in the United States: The Case of Occupational Status'. Social Science Research, 4: 329-360.

Ganzeboom, H. and D. Treiman (1996) 'Internationally Comparable Measures of Occupational Status for the 1988 International Standard Classification of Occupations'. Social Science Research, 25: 201-239.

Giddens, A. (1991) Modernity and Self-Identity. Cambridge: Polity Press.

Giddens, A. (2007) 'You need greater equality to achieve more social mobility', The Guardian, $24^{\text {th }}$, May.

Goldthorpe, J. H. (with Llewellyn, C. and C. Payne) (1987) Social Mobility and Class Structure in Modern Britain. Oxford: Clarendon Press.

Goldthorpe, J. H. (2007) On Sociology. Stanford, California: Stanford University Press.

Goldthorpe, J. H. (2013) 'Understanding - and Misunderstanding - Social Mobility in Britain: The Entry of the Economists, the Confusion of Politicians and the Limits of Educational Policy'. Journal of Social Policy, 42: 431-450.

Goldthorpe, J. H. and M. Jackson (2007) 'Intergenerational class mobility in contemporary Britain: political concerns and empirical findings'. British Journal of Sociology, 58(4): 526-546.

Goldthorpe, J.H. and C. Mills (2004) 'Trends in Intergenerational Class Mobility in Britain in the Late Twentieth Century', in Richard Breen (2004) (ed) Social Mobility in Europe, pp: 195-224. Oxford: Oxford University Press.

Goldthorpe, J. H. and C. Mills (2008) 'Trends in intergenerational class mobility in modern Britain: evidence from national surveys, 1972-2005'. National Institute Economic Review, 205: 83-100.

Gong, H. C., A. Leigh and X. Meng (2012) 'Intergenerational Income Mobility in Urban China'. Review of Income and Wealth, 58(3): 481-503.

Grusky, D. B. and R. M. Hauser (1984) 'Comparative social mobility revisited: models of convergence and divergence in 16 countries'. American Sociological Review 49: 19-38.

Heath, A. and Li, Y. (2014) Key Concepts in the Social Sciences: Social Mobility, forthcoming, Bristol: Polity.

Jonsson, J. and C. Mills (1993) 'Social Mobility in the 1970s and 1980s: A Study of Men and Women in England and Sweden'. European Sociological Review, 9: 229-248.

Lambert, P., K. Prandy and W. Bottero (2007) 'By Slow Degrees: Two Centuries of Social Reproduction and Mobility in Britain'. Sociological Research Online, 13:1. 
Kerckhoff, A., R. Campbell and I. Winfield-Laird (1985) 'Social Mobility in Great Britain and the United States'. American Journal of Sociology, 90(2): 281-308.

Li, Y. (2013) 'Social Class and Social Capital in China and Britain: A Comparative Study', Social Inclusion, 1(1): 59-71.

Li, Y. and F, Devine (2011) 'Is Social Mobility really declining?' Sociological Research Online, 12: 1-24.

Li, Y. and F. Devine (2014) 'Social Mobility in Britain, 1991-2011'. In L. Archer, A. Mann and J. Stanley (eds) Understanding Employer Engagement in Education: theories and evidence, pp. 79-91. London: Routledge.

Li, Y. and A. Heath (2014) 'Ethnic inequalities in social mobility', presentation at the House of Lords, London, 10 June.

Liu, J. (2008) 'Unequal chances in China's basic education and changes'. China Social Sciences, 5: 101-116 (in Chinese).

Lieberson, S. (1975) 'Rand-Sum Comparisons Between Group'. In D. Heise (ed.) (1976) Sociological Methodology, pp: 276-291. San Francisco: Jossey-Bass.

Marshall, G., A. Swift and S. Roberts (1997) Against the Odds? Social Class and Social Justice in Industrial Societies. Oxford: Clarendon Press.
Parish, W. (1981) 'Egalitarianism in Chinese Society’. Problems of Communism, 29: 37-53.

Parsons, T. (1967) Sociological Theory and Modern Society. New York: Free Press.

Rose, D. and D. Pevalin (2003) (eds) A Researcher's Guide to the National Statistics Socio-economic Classification. London: Sage.

Treiman, D. (1970) 'Industrialization and social stratification’. In E. O. Laumann (ed.) Social Stratification: Research and Theory for the 1970s, pp: 207-234. Indianopolis: Bobbs-Merril.

Treiman, D. (2012) 'The "difference between heaven and earth": Urban-rural disparities in well-being in China'. Research in Social Stratification and Mobility, 30: 33-47.

UNDP. (2010) Regional Report on Human Development. http://hdr. undp.org/en (accessed on 10 September 2012).

Wu, X. and D. Treiman (2007) 'Inequality and Equality under Chinese Socialism: The Hukou System and Intergenerational Occupational Mobility'. American Journal of Sociology, 113(2): 415-445.

Yu, H. and X. Liu (2004) 'Did the Effect of Work Unit on Intergenerational Mobility in Urban China Decline?' Sociological Studies (in Chinese), 6: 52-63. 